\title{
Relationship between Water Cement Ratio and Characteristic Properties of Multi Walled Carbon Nano Tube Reinforced Concrete
}

\author{
P. Mudasir, J. A. Naqash
}

\begin{abstract}
In this study effect of water-cement ratio (W/C) on the characteristic properties of multiwalled carbon nano tube reinforced concrete is analyzed. Five concrete mixtures of different water-cement ratio $(W / C)$ with and without carbon nano tubes (CNTs) were prepared. W/C of 0.40, 0.45, 0.48, 0.50 and 0.55 were used while quantity of carbon nano tube (CNT) was fixed at $1 \%$ by weight of cement (wbc). Ratio of cement, sand and aggregates was also fixed at 1: 1.76:2.66 in all mixes. For maintaining workability $0.5 \%$ polycarboxlate based superplasticizer wbc was added in all mixes.. The workability of carbon nanotube reinforced concrete (CNTC) reduced by $60 \%$ and $W / C=0.50$ was found ideal for slump as well as strength. At this $W / C$ compressive strength for CNTC increased by $7.20 \%$, split tensile strength increased by $25.75 \%$ and flexural strength increased by $3.87 \%$.
\end{abstract}

Key words: Multi walled carbon nanotubes, Water-Cement ratio, Concrete, Workability, Compressive strength, Split Tensile strength, Flexural strength, Porosity

\section{INTRODUCTION}

Functionalities of concrete improved with addition of nano materials. Incorporation of nano materials in concrete with advancement in nano technology resulted in nano modified concrete. Nano material, such as Carbon Nano Tubes (CNTs) has potential to modify mechanical properties of concrete.

Carbon nanotubes are byproduct of the fullerene synthesis discovered in 1991 at the NEC Fundamental Research Laboratory in Japan [1] . Graphite sheets are made of tubes such as zigzag, chiral, and armchair that can form a singlewalled or multi-walled nanotube, but remain as a hollow cylinder[2,3].

Carbon nano tubes have excellent mechanical properties with Young's modulus upto $1 \mathrm{TPa}$, tensile strength approximately $100 \mathrm{GPa}$ and fracture at a stain up to $15 \%$. CNT have a high

specific surface area with a value of up to $1000 \mathrm{~m}^{2} \mathrm{~g}^{-1}$ $[4,5,6]$. They also show very high thermal conductivity of $1700-3000 \mathrm{~W} / \mathrm{mk}$ and very low electrical resistivity of $5 \times 10^{-8}-2 \times 10^{-6}$

Revised Manuscript Received on March 17, 2020.

* Correspondence Author

Peerzada Mudasir H Dewani*, civil engineering department, National Institute of Technology,Srinager Kashmir, India. Email: mudasirdewani@gmail.com

Dr. Javed Ahmed Naqash, civil engineering department, National Institute of Technology,Srinager Kashmir, India

(C) The Authors. Published by Blue Eyes Intelligence Engineering and Sciences Publication (BEIESP). This is an open access article under the CC BY-NC-ND license (http://creativecommons.org/licenses/by-nc-nd/4.0/)
$\Omega \mathrm{m}$, similar to copper [7]. CNTs exhibit a low density even at high aspect ratio. They provide large interfacial contact area in matrix with- out much weight penalty like conventional fibers, hence reinforce concrete more efficiently $[8,9,10]$. They potentially restrain the propagation of small nano cracks and prevent crack initiation [11, 12].

Basic properties CNTs have shown growing interest for the development of smart concrete. Due to high surface area and strong van der wall force between CNT bundles they tend to agglomerate $\{13,14\}$. Therefore, the dispersion of CNTs play vital role for effective and innovative functionalities. For effective dispersion mechanical as well as chemical methods are employed. Mechanical methods involves ultra sonication, magnetic stirring, and even hand mixing, while chemical methods involves use of surfactants and functionalization $\{15\}$. But no proper method to guarantee full dispersion is reported.

At 0.4, 0.5 and 0.6 W/C Kim et al. [16] observed decrease in workability of mortar mixtures when $0.1 \%, 0.3 \%$ and $0.5 \%$ MWCNTs, by weight of cement was incorporated to them. Similarly at $0.5 \mathrm{~W} / \mathrm{C}$ Collins et al. [17] observed reduction of $14.5 \%, 32.8 \%$, and $48.9 \%$ in slump diameter with $0.5 \%$, $1 \%$, and $2 \%$ addition of MWCNTs respectively. When Maker and chan $\{18\}$ added $1 \%$ of SWCNTs by weight to cement they observed acceleration of hydration reaction of the C3S and change in morphology of C3A. Hydration reaction rate increased as CNTs act as nucleation sites for hydration products. Not only SWCNTs increases hydration rate but MWCNTs also increases hydration rate of cement as observed by Cui et al. $\{19\}$. They also reported hydration of cement accelerates with increasing MWCNTs content. When Bharj et al. [20] added 0.1\% MWCNTs, by weight, to concretes, and observed increment of 7,14,28 and 35 days compressive strength. 90 days compressive strength of was also enhanced by Hamzaoui et al. [21] with addition of $0.003 \%$ CNTs by weight to concretes. Tonder and Mafokoane [22] reported that at 28 days compressive strength increased by $13 \%, 20 \%$, and $9 \%$, while tensile strength increased upto $29 \%, 18 \%$, and $25 \%$, on adding $0.05 \%, 0.1 \%$, and $0.2 \%$ MWCNT respectively, by weight, to concrete. On contrary

Blue Eyes Intelligence Engineering \& Sciences Publication 
Table I:Details of Mixes

\begin{tabular}{|c|c|c|c|c|c|c|c|}
\hline Mixes & $\begin{array}{l}\text { W/C } \\
\text { Ratio }\end{array}$ & $\begin{array}{l}\text { Cement } \\
\mathrm{kg} / \mathrm{m}^{3}\end{array}$ & $\begin{array}{c}\text { Effective } \\
\text { Water } \mathrm{kg} / \mathrm{m}^{3}\end{array}$ & $\begin{array}{l}\text { Coarse } \\
\text { Aggregate } \\
\mathrm{kg} / \mathrm{m}^{3}\end{array}$ & $\begin{array}{c}\text { Fine } \\
\text { Aggregate } \\
\mathrm{kg} / \mathrm{m}^{3}\end{array}$ & SP \%wbc & CNT \% Wbc \\
\hline REF 55 & 0.55 & \multirow{10}{*}{430} & 237 & \multirow{10}{*}{1145} & \multirow{10}{*}{760} & \multirow{10}{*}{0.5} & ------- \\
\hline CNTC 55 & & & 237 & & & & 1 \\
\hline REF 50 & 0.5 & & 215 & & & & --------- \\
\hline CNTC 50 & & & 215 & & & & 1 \\
\hline REF 48 & 0.48 & & 206 & & & & ------- \\
\hline CNTC 48 & & & 206 & & & & 1 \\
\hline REF 45 & 0.45 & & 193 & & & & ------- \\
\hline CNTC 45 & & & 193 & & & & 1 \\
\hline REF 40 & 0.4 & & 172 & & & & ------- \\
\hline CNTC 40 & & & 172 & & & & 1 \\
\hline
\end{tabular}

when Madhavi et al. [23] added 0.015\%, 0.03\% and $0.045 \%$ MWCNTs by weight, to concretes and observed $2.75 \%, 16.38 \%$ and $26.69 \%$ enhancement of 28 day compressive strength and $30.84 \%, 45.37 \%$ and $66.3 \%$, increment in split tensile strength respectively.

Analysis on the properties of CNT incorporated concrete is not over as little literature is available. Comprehensive studies about the influence of Water Cement ratio on the strength CNT reinforced concrete have never been discussed. Also influence of CNTs on split tensile strength and flexural strength have been rarely disused. Also no relationship between $\mathrm{W} / \mathrm{C}$ and characteristic strengths of concrete is derived till now. Considering it as a difficulty for researchers the authors has taken an initiative to investigate role of water-cement (W/C) ratio and its influence on fresh and hardened properties of CNT reinforced concrete. For this cause concretes with different $\mathrm{W} / \mathrm{C}$ ratio were characterized bearing $1 \%$ on pristine multi walled CNTs by weight of cement (wbc). The Optimal amount of CNT was selected on the basis ofprevious works done, as very little work is done on $1 \%$ CNT wbc in concrete.

First part of result and discussion compares characteristics properties of reference concrete and CNT reinforced ConcreteWhile in second part relationship between W/C ratio and characteristics properties of CNT reinforced Concrete is obtained.

\section{EXPERIMENTAL PROGRAMS}

\section{A. Materials}

For concrete production Ordinary Portland Cement of Type I, crushed aggregates of 20mm nominal size and coarse sand of Zone II grade according to IS8112:2013 and IS 383:2016 were used. Multi walled carbon nano tubes (CNTs) of $97 \%$ purity and diameter of 5-15nm were used. For maintaining workability superplasticizer (SP) based on polycarboxylate was used.

\section{B. Dispersion procedure of multi walled CNTs}

Multi walled carbon nano tubes were procured in powder form and to deagglomerate CNT clusters sonication was conducted. The CNTs were first dispersed in 30\% of mixing water and continuously stirred for 10 minutes. The optimum ratio by weight CNT/Water was $1: 35$. Sonication time was 20 minutes for each sample from whole mixture.

\section{Concrete composition and mixing.}

Five concretes with W/C of $0.40,0.45,0.48,0.50$ and 0.55 and ratio of cement: sand: aggregates fixed at 1: 1.76:2.66 were produced to study the influence of $\mathrm{W} / \mathrm{C}$ ratio on workability of carbon nano tube incorporated concrete (CNTC). In addition to cement, sand and aggregates, 1\% CNT by weight of cement was added to CNTC and concrete without CNT was produced for comparison and termed as reference concrete. Compositions details are shown in table I. For concrete production aggregates was thoroughly washed and dried. The cement, sand, and aggregates were dry mixed for 2 minutes and then remained $70 \%$ of mixing water was added. Simultaneously dispersed CNT solution was also added. The plasticizer (SP) was already mixed in $70 \%$ of remained water. The whole mixing was carried for 5-7 minutes. After mixing the slump was measured using slump cone test according to IS 1199:1959 \{Reaffirmed 2004\}. The denomination in table I include mixes produced with different $\mathrm{W} / \mathrm{C}$ ratio where ' $\mathrm{REF}$ ' represent reference concrete and 'CNTC' represent CNT reinforced concrete while numeric digits represent $\mathrm{W} / \mathrm{C}$ ratio. Three $150 \mathrm{~mm}$ cube specimens for compressive strength test, three $150 \times 300 \mathrm{~mm}$ cylindrical specimens for split tensile strength test and three $150 \times 150 \times 700 \mathrm{~mm}$ beam specimen for flexure test at 28 days were prepared .After at $24 \mathrm{~h}$, specimens were demoulded and kept in water curing at room temperature $25 \pm 2^{\circ} \mathrm{C}$ for 28days.

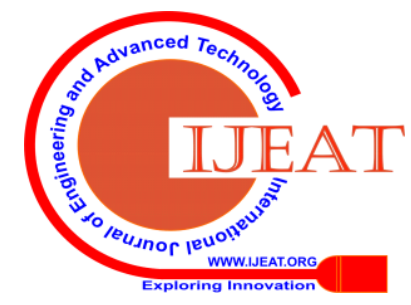




\section{RESULTS AND DISCUSSION}

A. Comparison between characteristic properties of reference concrete and CNT reinforced Concrete

\section{Workability}

The addition of CNTs caused drastic decrease in workability. Slump increased with increment of water and with $\mathrm{W} / \mathrm{C} \geq 0.50$, reference concrete attained self compacting state or flow concrete state. But at $\mathrm{W} / \mathrm{C}=0.50 \mathrm{CNTC}$ didn't attained flow state like that of reference concrete because the some water was entrapped in agglomerates due to which slump was less than reference concrete. Its observed that the workability of CNTC reduced by $60 \%$ in comparison to reference concrete at a particular $\mathrm{W} / \mathrm{C}$ ratio as observed from table II and figure 1 . Also the variation of up to $\pm 2 \mathrm{~cm}$ was observed in between the mixes with change of W/C as observed for table II. The decrease in workability of nano modified concrete can be attributed to high specific surface area and surface tension property of nano particles $\{24,25\}$. Due to surface tension and hydrophobic nature the water get clinged around the nano particles, thereby reducing their specific surface area. Also as per literature dispersion of CNT in matrix plays vital role in modification of functionalities of concrete. If they are not well dispersed water gets entrapped in agglomerated state. As the specific surface area of nano particles reduces due to agglomerates, therefore full interaction CNTs with matrix and improvement in desired properties is not attained $\{26\}$. Amount of CNT also plays vital role in dispersion and workability of concrete $\{16,27\}$.

Table II: Result for slump

\begin{tabular}{|c|c|c|}
\hline W/C & Ref slump & CNTC slump \\
\hline 0.55 & 122 & 75 \\
\hline 0.50 & 118 & 72.5 \\
\hline 0.48 & 115 & 69.5 \\
\hline 0.45 & 112.5 & 68 \\
\hline 0.40 & 100 & 65 \\
\hline
\end{tabular}

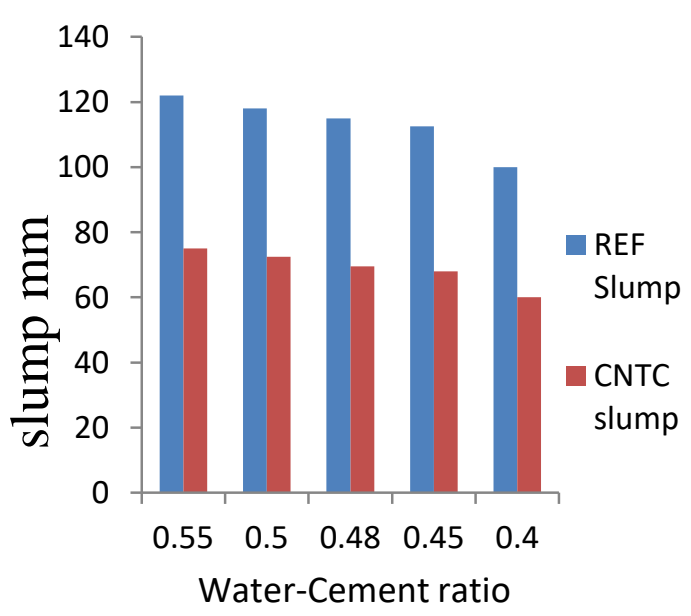

Fig 1. Slump increment with $\mathrm{W} / \mathrm{C}$ ratio

Compressive, Split Tensile and Flexural Strength.
The compressive strength test was conducted as per IS 4161959 on cubes of size $150 \times 150 \times 150 \mathrm{~mm}$. The split tensile strength test was conducted on $300 \times 150 \mathrm{~mm}$ cylinder as per IS 5816-1999. The flexural strength test using three point loading method was performed as per IS 516:1959. The maximum failure load and its failure pattern are noted and results are presented in table III, table IV and table V respectively.

The strength test was performed on specimens with $\mathrm{W} / \mathrm{C} \geq 0.45$ because $\mathrm{W} / \mathrm{C}=0.40$ is used for hydration of cement. At $\mathrm{W} / \mathrm{C}=0.40$ Tri Calcium Aluminate i.e. $\mathrm{C}_{3} \mathrm{~A}$ is formed which is responsible for early strength development. The excess water (i.e. water greater than 0.40 ) remains in capillary pore and evaporates. This phenomenon is called capillary porosity and is responsible for decrease in strength. It is observed as slump increases with W/C ratio strength decreases as stated above. So $\mathrm{W} / \mathrm{C}=0.50$ is ideal for slump as well as for strength. At this W/C compressive strength for CNTC increased by $7.20 \%$, split tensile strength increased by $25.75 \%$ and flexural strength increased by $3.87 \%$. So the strength achieved at $\mathrm{W} / \mathrm{C}=0.48$ in reference concrete is achieved at $\mathrm{W} / \mathrm{C}=0.50$ in $\mathrm{CNTC}$.

Table III:Detailed result of Compressive strength

\begin{tabular}{|c|c|c|c|c|c|}
\hline & \multicolumn{2}{|c|}{ Ref concrete } & \multicolumn{2}{c|}{ CNT Concrete } & \\
\hline $\begin{array}{c}\text { W/C } \\
\text { ratio }\end{array}$ & $\begin{array}{c}\text { Failure } \\
\text { load kN }\end{array}$ & Mpa & $\begin{array}{c}\text { Failure } \\
\text { load kN }\end{array}$ & Mpa & $\begin{array}{c}\% \\
\text { increase } \\
\text { in } \\
\text { strength }\end{array}$ \\
\hline 0.45 & 1013 & 45 & 1094 & 48 & 8 \\
\hline 0.48 & 960 & 42 & 1012 & 44 & 7.20 \\
\hline 0.50 & 855 & 38 & 913 & 40 & 6.87 \\
\hline 0.55 & 805 & 35 & 862 & 38 & 7 \\
\hline
\end{tabular}

Table IV:Detailed result of split tensile strength

\begin{tabular}{|c|c|c|c|c|c|}
\hline & \multicolumn{2}{|c|}{ Ref concrete } & \multicolumn{2}{|c|}{ CNT Concrete } & \\
\hline $\begin{array}{c}\text { W/C } \\
\text { ratio }\end{array}$ & $\begin{array}{c}\text { Failure } \\
\text { load kN }\end{array}$ & Mpa & $\begin{array}{c}\text { Failure } \\
\text { load kN }\end{array}$ & Mpa & $\begin{array}{c}\% \\
\text { increase } \\
\text { in } \\
\text { strength }\end{array}$ \\
\hline 0.45 & 186 & 2.63 & 237 & 3.35 & 27 \\
\hline 0.48 & 160 & 2.26 & 201 & 2.84 & 25.75 \\
\hline 0.50 & 150 & 2.12 & 190 & 2.68 & 26.87 \\
\hline 0.55 & 138 & 1.95 & 173 & 2.44 & 25 \\
\hline
\end{tabular}

Table V:Detailed result of flexural strength

\begin{tabular}{|c|c|c|c|c|c|}
\hline & \multicolumn{2}{|c|}{ Ref concrete } & \multicolumn{2}{|c|}{ CNT Concrete } & \\
\hline $\begin{array}{c}\text { W/C } \\
\text { ratio }\end{array}$ & $\begin{array}{c}\text { Failure } \\
\text { load kN }\end{array}$ & Mpa & $\begin{array}{c}\text { Failure } \\
\text { load kN }\end{array}$ & Mpa & $\begin{array}{c}\% \\
\text { increase } \\
\text { in } \\
\text { strength }\end{array}$ \\
\hline 0.45 & 15 & 6 & 15.75 & 6.3 & 5 \\
\hline 0.48 & 14 & 5.6 & 14.54 & 5.81 & 3.87 \\
\hline 0.50 & 13.5 & 5.4 & 14.10 & 5.64 & 4.5 \\
\hline 0.55 & 12 & 4.8 & 12.36 & 5 & 3 \\
\hline
\end{tabular}

As observed from tables III, IV and V the strength reduced with increase of $\mathrm{W} / \mathrm{C}$ in both reference concrete as well as CNTC.

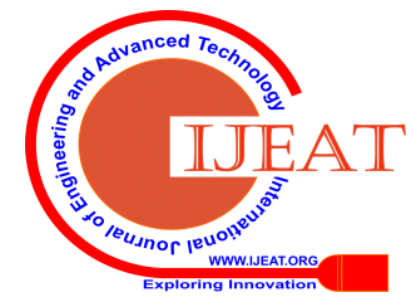


But the strength of CNTC was higher than reference concrete as shown in figure 2, 3 and 4 . The increment in strength of CNTC is attributed to incorporation of CNTs as they have tensile strength from 20 Gpa to 100Gpa which in turn increases strength of matrix. As they act as filler the spaces between hydration products is filled which increases strength. $\{28,29\}$. Due to nucleation they provide strong links between hydration products which accelerate C-S-H formation $\{30\}$. Due to bridging effect propagation of micro cracks resists and subsequent growth to the macro scale $\{31\}$. The decreases in strength of CNTC with increment of W/C can also be attributed to porosity caused by evaporation of entrapped water from agglomerates $\{32\}$. As $\mathrm{W} / \mathrm{C}$ increases excess water get entrapped and evaporates causing porosity, thus decreasing the strength. But due to formation of strong links between hydration products, the strength of CNTC is higher than reference concrete as observed in this research

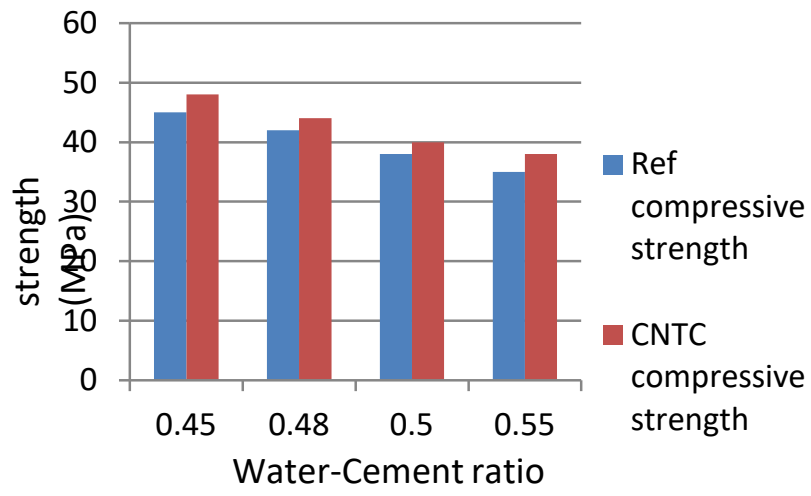

Fig 2. Comparison between compressive strength of Reference concrete and CNT reinforced concrete

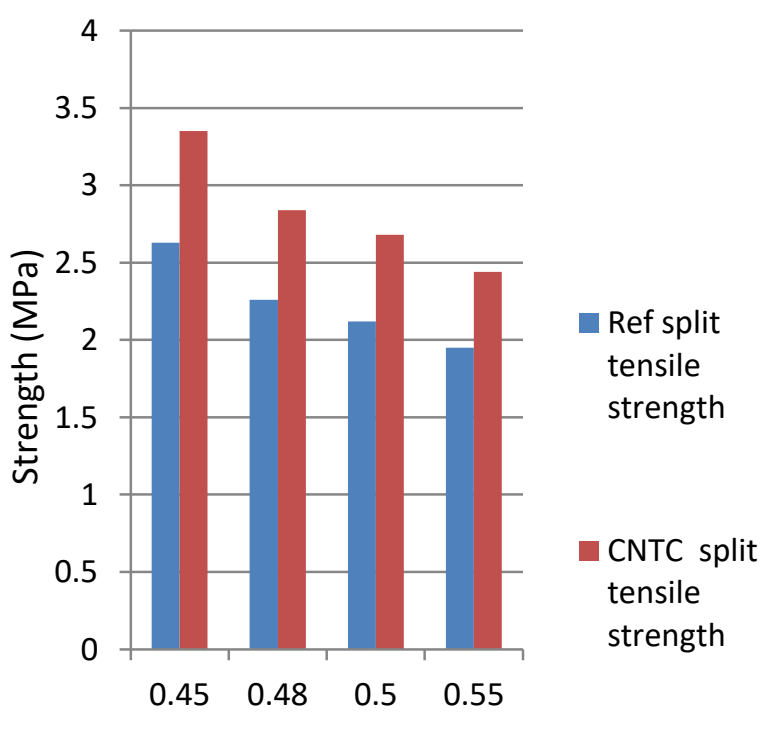

Water-Cement ratio

Fig. 3 Comparison between Split tensile strength of Reference concrete and CNT reinforced Concrete.

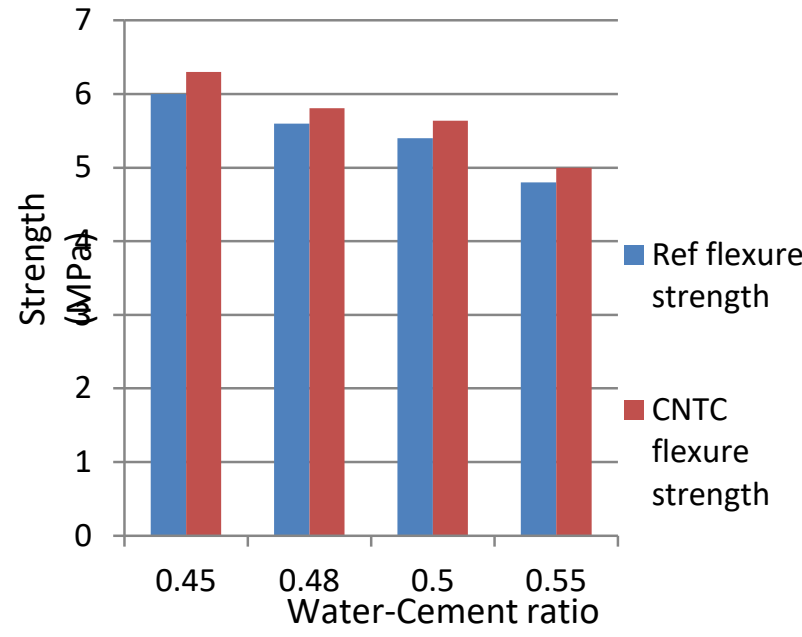

Fig. 4 Comparison between Flexural strength of Reference concrete and CNT reinforced Concrete.

B. Relationship between $\mathrm{W} / \mathrm{C}$ ratio and Hardened properties of CNT reinforced Concrete

H.K.Kim et. al [33] derived relationship between compressive strength and porosity of CNT/cement composites and found $\mathrm{R}^{2}$ was less than 0.6.

From figure 5, 6 and 7 relationship between W/C and hardened properties (i.e compressive, split tensile , and flexural strength) of CNTC were fabricated. By fitting experimental data in respective equations and tracing them values of constants terms of equations is obtained and are catalogued in table VI. In particular $\mathrm{R}^{2}$ was as high as 0.9 in this study. High value of $\mathrm{R}^{2}$ can be attributed to interaction between CNT and hydration product and bridging effect of CNT. Further investigation needs to be done in terms of varying CNT content, grade of concrete and length of fibers.

Table VI: Relationship equations

\begin{tabular}{|c|c|c|c|c|}
\hline Equation & \multicolumn{3}{|c|}{ Variable obtained } & $\mathrm{R}^{2}$ \\
\hline & $\mathrm{a}$ & $\mathrm{b}$ & $\mathrm{c}$ & \\
\hline $\mathrm{fck}=\mathrm{Ax}^{2}+\mathrm{Bx}+\mathrm{C}$ & 943 & -1046 & 328.1 & 0.9 \\
\hline $\mathrm{fct}=\mathrm{Ax}^{2}+\mathrm{Bx}+\mathrm{C}$ & 95.53 & -104.5 & 31.02 & 0.9 \\
\hline $\mathrm{fcr}=\mathrm{Ax}^{2}+\mathrm{Bx}+\mathrm{C}$ & 19.48 & -32.28 & 16.86 & 0.9 \\
\hline
\end{tabular}

Where fck=compressive strength, fct=split tensile strength,fcr=flexural strength a,b,c =variable obtained by linear regression.

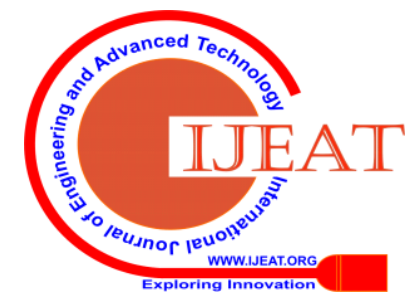




\section{Compressive Strength}

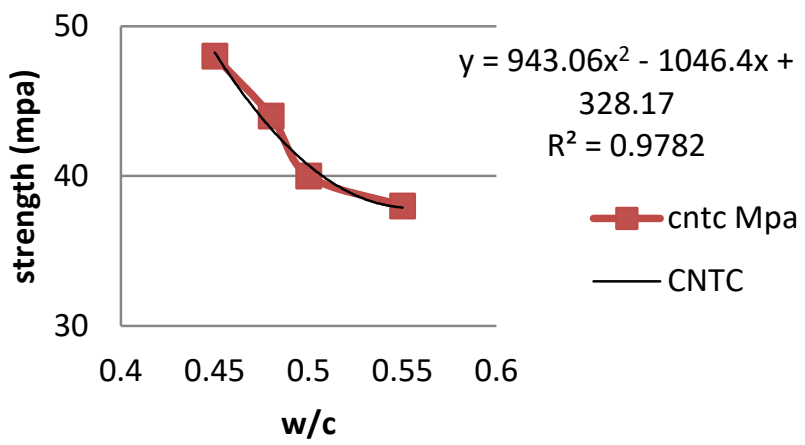

Fig. 5 Relationship between Compressive strength and Water cement ratio

\section{CONCLUSION}

- The workability improved with increases $\mathrm{W} / \mathrm{C}$ ratio as slump increased. But at $\mathrm{W} / \mathrm{C}=0.50$ reference concrete attained flow state

- The workability of CNTC was reduced by $60 \%$ due to entrapment of water molecules in agglomerates.

- $\quad$ As strength reduced with increase of W/C ratio in both reference concretes as well as CNTC, but the strength of CNTC was higher than reference concrete

- The decrease in strength of compositions is due to capillary porosity as it increases at $\mathrm{W} / \mathrm{C} \geq 0.40$.

\section{Split Tensile Strength}

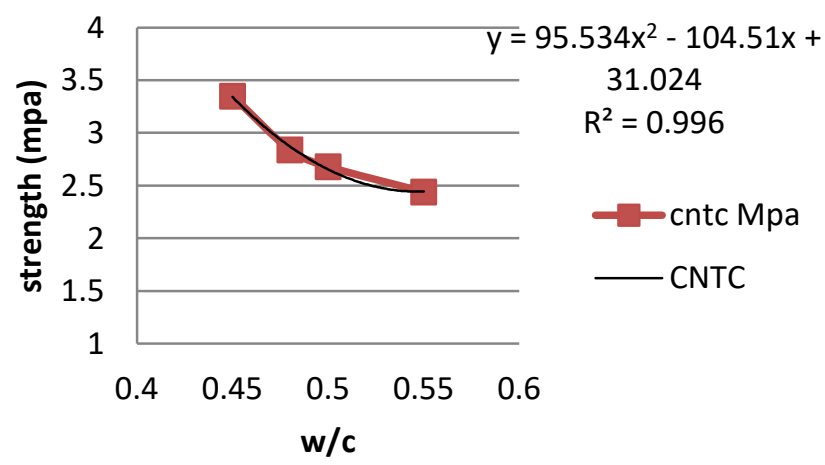

Fig. 6 Relationship between split tensile strength and Water-Cement Ratio

\section{Flexural strength}

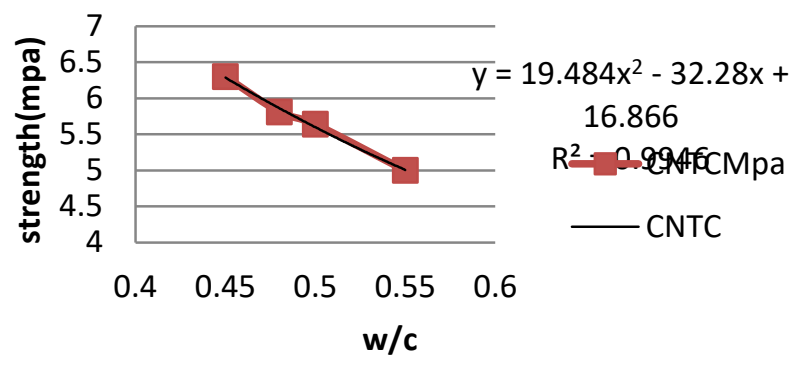

Fig. 7 Relationship between Flexural strength and Water-Cement Ratio

- $\mathrm{W} / \mathrm{C}=0.50$ is ideal for slump as well as strength. At this W/C compressive strength for CNTC increased by $7.20 \%$, split tensile strength increased by $25.75 \%$ and flexural strength increased by $3.87 \%$.

- $\quad$ The decrease in strength due to capillary porosity is balanced by CNTs in case of CNTC, as CNTs provide bridging effect.

\section{REFERENCES}

1. Iijima S. Helical microtubules of graphitic carbon. Nature 1991;354(6348):56-58.

2. M. Esawi Amal, Mahmoud M. Farag, Carbon nanotube reinforced composites: potential and current challenges, Mater. Des. 28 (9) (2007) 2394-2401.

3. B. Wang, Y. Han, and S. Liu, "Effect of highly dispersed carbon nanotubes on the flexural toughnessof cement-based composites," Constr. Build. Mater., vol. 46, pp. 8-12, 2013.

4. Salvetat, J.P.; Bonard, J.M.; Thomson, N.H.; Kulik, A.J.; Forro, L.; Benoit, W.; Zuppiroli, L. Mechanical properties of carbon nanotubes. Appl. Phys. A 1999, 69, 255-260.

5. Belytschko, T.; Xiao, S.P.; Schatz, G.C.; Ruoff, R.S. Atomistic simulations of nanotube fracture. Phy. Rev. B 2002, 65, 235430 235438.

6. Kaushik, B.K.; Goel, S.; Rauthan, G. Future VLSI interconnects: Optical fiber or carbon nanotube-A review. Microelectron. Int 2007, 24, 53-63.

7. Choi ES, Brooks JS, Eaton DL, Al-Haik MS, Hussaini MY, Garmestani H, et al. Enhancement of thermal and electrical properties of carbon nanotube polymer composites by magnetic field processing J Appl Phys 2003; 94(9):6034-9

8. AB. Dalton, S. Collins, E. Munoz, JM. Razal, VH. Ebron, JP Ferraris, Nature 423 (6941) (2003) 703

9. Q. Wang, J. Dai, W. Li, Z. Wei, J. Jiang, Compos. Sci. Technol. 68 (2008) 1644- 1648 .

10. A. Dikshit, J. Samuel, RE. DeVor, SG. Kapoor, J. Manuf. Sci. Eng. 130 (2008) 0311151-0311158

11. M.S. Konsta-Gdoutos, Z.S. Metaxa, S.P. Shah, Multi-scale mechanical and fracture characteristics and early-age strain capacity of high performance carbon nanotube/cement nanocomposites, Cem. Concr. Compos. 32 (2010) 110-115, https://doi.org/10.1016/j.cemconcomp.2009.10.007.

12. Y. Hu, D. Luo, P. Li, Q. Li, G. Sun, Fracture toughness enhancement of cement paste with multi-walled carbon nanotubes, Constr. Build. $\begin{array}{llll}\text { Mater. } & 70 & \text { (2014) 332-338, }\end{array}$ https://doi.org/10.1016/j.conbuildmat.2014.07.077.

13. A. Cwirzen, K. Habermehl-Cwirzen, V. Penttala, Surface decoration of carbon nanotubes and mechanical properties of cement/carbon nanotube composites, Adv. Cem. Res. 20 (2008) 65-73, https://doi.org/10.1680/adcr.2008.20.2.65.

14. L.I. Nasibulina, I.V. Anoshkin, A.G. Nasibulin, A. Cwirzen, V. Penttala, E.I. Kauppinen, Effect of carbon nanotube aqueous dispersion quality on mechanical properties of cement composite, J. Nanomater. 2012 (2012), https://doi.org/10.1155/2012/169262.

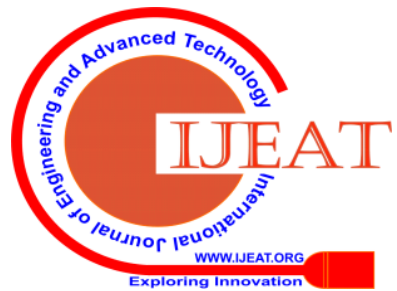


15. A. H. Korayem, N. Tourani, M. Zakertabrizi, A. M. Sabziparvar, and W. H. Duan, "A review of dispersion of nanoparticles in cementitious matrices: Nanoparticle geometry perspective," Constr. Build. Mater., vol. 153, pp. 346-357, 2017.

16. H.K. Kim, I.S. Park, H.K. Lee, Improved piezoresistive sensitivity and stability of CNT/cement mortar composites with low waterbinder ratio, Compos. Struct. 116 (2014) 713 -719.

17. Collins Frank, Lambert John, Duan Wen Hui, The influences of admixtures on the dispersion, workability, and strength of carbon nanotube-OPC paste mixtures, Cement Concr. Compos. 34 (2012) 201-207.

18. Jonathan M. Markar, Gordon W. Chan, Growth of cement hydration products on single walled carbon nanotubes, J. Am. Ceram. Soc. 92 (6) (2009) 1303- 1310.

19. Cui Hongzhi, Yang Shuqing, Memon Shazim Ali, Development of carbon nanotube modified cement paste with microencapsulated phase-change material for structural-functional integrated application, Int. J. Mol. Sci. 26 (2015) 8027-8039.

20. Bharj Jyoti, Singh Sarabjit, Chander Subhash, Singh Rabinder, Experimental study on compressive strength of cement-CNT composite paste, Indian J. Pure Appl. Phys. 52 (2014) 35-38.

21. R. Hamzaoui, A. Bennabi, S. Guessasma, M.R. Khelifa, N. Leklou, Optimal carbon nano tubes concentration incorporated in mortar and concrete, Adv. Mater. Res. 587 (2012) 107-110.

22. P. Van Tonder, T.T. Mafokoane, Effects of multi-walled carbon nanotubes on strength and interfacial transition zone of concrete, Constr. Mater. Struct. (2014) 718-727.

23. T.C.H. Madhavi, P. Pavithra, Singh Sushmita Baban, Raj S.B. Vamsi, Paul Surajit, Effect of multiwalled carbon nanotubes on mechanical properties of concrete, Engineering 2 (6) (2013) 166-168

24. H.Madani, A.Bagheri,T.Parhizkar, The pozzolanic reactivity of mono dispersed nanosilica hydrosols and their influence on the hydration characteristics of Portland cement , Cem.Conr.Res. 42 (2012) 15631570.

25. I.Papayianni, V.Pachta, M.Stefaniduo, Experimental study of nanomodified limebased grouts, World J. Eng. 9 (2012) 501-508.

26. S. Kawashima et al., Dispersion of $\mathrm{CaCO} 3$ nanoparticles by sonication and surfactant treatment for application in fly-ash cement system , Mater.Struct.47(6) (2014)1011-1023.

27. A. Carriço, J. A. Bogas, A. Hawreen, and M. Guedes, Durability of

28. multi-walled carbon nanotube reinforced concrete , Constr. Build. Mater., vol.164, pp. 121-133, 2018.

29. 17] T. Nochaiya, A. Chaipanich, Behavior of multi-walled carbon nanotubes on the porosity and microstructure of cement-based materials, Appl. Surf. Sci. 257 (2011) 1941-1945, https://doi.org/10.1016/j.apsusc.2010.09.030.

30. S. Parveen, S. Rana, R. Fangueiro, A review on nanomaterial dispersion, microstructure, and mechanical properties of carbon nanotube and nanofiber reinforced cementitious composites, J. Nanomater. 2013 (2013)

31. J.M. Makar, The Effect of SWCNT and Other Nanomaterials on Cement Hydration and Reinforcement, in: Nanotechnol. Civ. Infrastruct., 2011.

32. A. Yazdanbakhsh, Z. Grasley, B. Tyson, R. Abu Al-Rub, Challenges and benefits of utilizing carbon nanofilaments in cementitious materials, J. $\quad$ Nanomater. $2012 \quad$ (2012), https://doi.org/10.1155/2012/371927.

33. Kim GM, Naeem F, Kim H,Lee HK, Heating and heat-dependent mechanical characteristics of CNT-embedded cementitious composites .Compos. struct. 2016:136-162-70.

34. H. K. Kim, I. W. Nam, and H. K. Lee, "Enhanced effect of carbon nanotube on mechanical and electrical properties of cement composites by incorporation of silica fume," Compos. Struct., vol. 107, pp. 60-69, 2014.

\section{AUTHORS PROFILE}

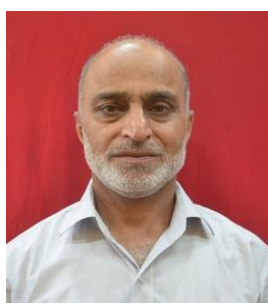

Dr. Javed Ahmed Naqash is an Associate Professor at Department of Civil Engineering, National Institute of Technology Srinagar Kashmir, India. He has done his PhD from IIT Roorkee. He has teaching experience of 30 yrs. He is an expert in concrete technology and his area of research includes 'silica fume in concrete', ' nano zeolite in concrete', 'effect of admixtures and plasticizers on concrete' and many more whose papers are available in scopus indexed journal. Currently he's guiding 5-6 Phd scholars on various topics of concrete. He has guided more than 100 students PG level. He is consultant to various structural design organizations. He is visiting professor and examiner to various institutes of state

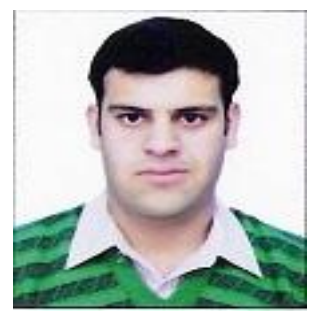

Peerzada Mudasir Hussain Dewani is Doctoral Research Fellow at Department of Civil Engineering, National Institute of Technology Srinagar Kashmir, India. He has done his masters from Galgotias university Noida. He has teaching experience of 3 yrs $\mathrm{He}$ is an expert in concrete technology and his area of research includes 'steel fibers in concrete', ' nano zeolite in concrete', 'effect of admixtures and plasticizers on concrete', ' CNT in concrete' and many more . He has guided dozen of students UG level. He has guided 4-5 students at PG level. $\mathrm{He}$ is consultant to various structural design organizations. He is visiting lecturer and examiner to various institutes of state.

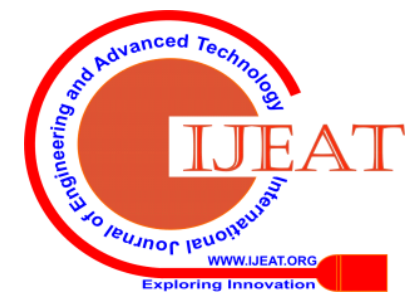

